\title{
The effectiveness of stress management training on blood glucose control in patients with type 2 diabetes
}

Fereshteh Zamani-Alavijeh ${ }^{1}$, Marzieh Araban ${ }^{2,3}$, Hamid Reza Koohestani ${ }^{4}$ and Mahmood Karimy ${ }^{4^{*}}$

\begin{abstract}
Background: Type 2 diabetes is a chronic disease that is expanding at an alarming rate in the world. Research on individuals with type 2 diabetes showed that stressful life events cause problems in the effective management and control of diabetes. This study aimed at investigating the effect of a stress management intervention on blood glucose control in individuals with type 2 diabetes referred to Zarandeh clinic, Iran.
\end{abstract}

Methods: In this experimental study, 230 individuals with type 2 diabetes (179 female and 51 male) were enrolled and assigned to experimental $(n=115)$ and control $(n=115)$ groups. A valid and reliable multi-part questionnaire including demographics, Perceived Stress Scale, Coping Inventory for Stressful Situations, Coping Self-Efficacy Scale, and multidimensional scale of perceived social support was used to for data collection. The experimental group received a training program, developed based on the social cognitive theory and with an emphasis on improving self-efficacy and perceived social support, during eight sessions of one and a half hours. Control group received only standard care. Data were analyzed using SPSS 15 applying the $t$ test, paired t-tests, Pearson correlation coefficient, and Chi square analysis. The significance level was considered at 0.05 .

Results: Before the intervention, the mean perceived stress scores of the experimental and control groups were $33.9 \pm 4.6$ and $35 \pm 6.5$, respectively, and no significant difference was observed $(p>0.05)$. However, after the intervention, the mean perceived stress score of the experimental group (26.7 \pm 4.7$)$ was significantly less than that of the control group (34.5 \pm 7$)(p=0.001)$. Before the intervention, the mean scores of HbA1c in the experimental and control groups were $8.52 \pm 1$ and $8.42 \pm 1.2$, respectively, and there was no significant difference between the two groups. However, after the intervention, the results showed a significant decrease in glycosylated hemoglobin levels in the experimental group $(p \leq 0.05)$. Moreover, after the intervention, the result showed a significant difference between the mean scores of all aspects of Coping Inventory for Stressful Situations, coping self-efficacy, and perceived social support in the two groups $(p<0.05)$.

Conclusion: Our results suggested that the theory-based stress management intervention based on social cognitive theory may help to decrease stress and increase coping self-efficacy, stress management, perceived social support, and lead to a reduction in the glycosylated hemoglobin levels among patients with diabetes.

Keywords: Diabetes, Education, Social cognitive theory, Stress management, Self-efficacy

\footnotetext{
*Correspondence: karimymahmood@yahoo.com

${ }^{\dagger}$ Fereshteh Zamani-alavijeh and Marzieh Araban equal first authorship

${ }^{4}$ Social Determinants of Health Research Center, Saveh University

of Medical Sciences, Saveh, Iran

Full list of author information is available at the end of the article
}

(c) The Author(s) 2018. This article is distributed under the terms of the Creative Commons Attribution 4.0 International License (http://creativecommons.org/licenses/by/4.0/), which permits unrestricted use, distribution, and reproduction in any medium, provided you give appropriate credit to the original author(s) and the source, provide a link to the Creative Commons license, and indicate if changes were made. The Creative Commons Public Domain Dedication waiver (http://creativecommons.org/ publicdomain/zero/1.0/) applies to the data made available in this article, unless otherwise stated. 


\section{Background}

Type 2 diabetes is a chronic disease that is expanding at an alarming rate in the world. The International Diabetes Federation reports that the prevalence of diabetes has reached a global epidemic level [1].

Today, more than 415 million people in the world suffer from diabetes, which is projected to hit 642 million by 2040 [2]. The highest prevalence of diabetes has been observed in the Middle East and North Africa Region (MENA region), where Iran is located. According to the latest estimates, 35.4 million people ( $9.1 \%$ of adults) in this region have diabetes, which is predicted to double by the year 2030. Surprisingly, Iran is ranked third in the MENA region, in terms of the total number of adults with diabetes [2]. WHO has reported the prevalence of diabetes among Iranian men and women as 9.8 and 11.1\%, respectively [3, 4]. According to WHO, currently about 3 million Iranians have diabetes and if effective action is not taken, this figure will reach 7 million by 2030. This disease is the most common cause of amputation, blindness, and chronic renal failure and it is a risk factor for developing heart disease [5].

In addition, the financial burden of diabetes has a wide range. In Canada, it was around $\$ 2.3$ billion in 2010 and it is expected to reach $\$ 4.7$ billion by 2020 . Hence, diabetes is also an economic problem. In the US, the total cost of diabetes was around \$ 174 billion in 2007, of which direct (medical) and indirect costs accounted for $\$$ 116 billion and $\$ 58$ billion, respectively $[6,7]$. The direct costs include doctor visits, paraclinical tests, medication, surgery, hospital stays, etc. while the indirect costs include reduced productivity, disability and early death [1].

Stress is one of the main problems among patients with diabetes. Several studies have shown that stress and psychological distress play an important role in the development, intensification, and chronicity of diabetes [8]. Stress plays a dual role (cause and effect) in its relationship with diabetes. In other words, stress can be considered as a cause and yet a consequence of diabetes [9]. On one hand, stress increases glucose and glycosylated hemoglobin (HbA1C) and, on the other hand, diabetes and its consequences can increase stress levels among individuals with type 2 diabetes as well as causing other physical, behavioral, and mental disorders [10, 11]. The results of Eren's research showed that people with diabetes experience higher levels of stress and anxiety, compared to healthy people [10]. According to the study conducted by Bradley on diabetic patients, stressful events in life cause problems in the effective management and control of diabetes [11]. Moreover, stress has been reported to elevate blood glucose levels. The hypothalamic pituitary adrenal (HPA) axis, as the central stress response system in humans, governs the neuroendocrine adaptation component of the stress response via a straightforward function. The hypothalamic release of corticotropin-releasing factor (CRF) is the main representation of this response. After binding to CRF receptors on the anterior pituitary gland, CRF (also known as $\mathrm{CRH}$ or corticotropin-releasing hormone) releases adrenocorticotropic hormone (ACTH). This hormone, in turn, binds to receptors on the adrenal cortex and leads to cortisol release. Cortisol is released in response to stress and stimulates the formation of glucose and glycogenolysis, leading to high blood glucose levels [12].

Because feminization with adaptive measures in coping with the stress associated with chronic diseases such as diabetes is not an easy task, patients face many problems associated with management of this disease; as it affects all aspects of personal life, including nutrition, exercise, occupation, recreation and family, and social life [13]. Studies show that about $20-40 \%$ of outpatient individuals with type 2 diabetes experience some degrees of stress and depression. Low levels of emotional and psychological health lead these patients to other problems such as increased likelihood of complications and increased mortality rates [14]. Braun et al. [15] argue that all patients with diabetes should participate in structured training and follow-up programs to improve their metabolic control and quality of life. The positive effects of blood glucose control have been proven in promoting the health of individuals with type 2 diabetes; therefore, some interventions should be designed to achieve this goal. Various theories and models have been proposed in the area of behavior change and health promotion planning. The social cognitive theory is among these theories. This model has some self-efficacy constructs for performing an activity and perceived social support [16]. Today, selfefficacy has a high status in different aspects of life and health and plays an important role in dealing with mental health problems as well as in stress and depression coping decisions. A strong self-efficacy leads to relaxation and can be a good predictor of mental health [17]. In social psychology, social support is recognized as a facilitator of healthy behavior. The effective role of social support has been proven in health, social, and psychological adaptation and in the reduction of stress and depression in chronic diseases [18]. Gao et al. showed that social support and self-efficacy in individuals with type 2 diabetes are correlated with adherence to self-care behaviors and as well as with adaptation to diabetes [18].

The present study was conducted to investigate the effect of the social cognitive theory-based intervention on blood glucose control in individuals with type 2 diabetes. In this regard, both self-efficacy and social support are effective in stress management and reduction. 
According, the social cognitive theory was used in this work since it covers both these constructs.

\section{Methodology \\ Design and sample}

The population of the current experimental study included all the diabetic patients admitted to Zarandieh County Diabetes Clinic $(\mathrm{N}=420,105$ males and 315 females).

The inclusion criteria included having high-stress scores $(\geq 28)$ based on the perceived stress scale, not having symptoms of severe psychiatric disorders, lack of late-stage complications of diabetes such as cardiovascular diseases, foot ulcers, eye problems, no history of diabetic coma, hemoglobin A1c levels above 7\%, and signing informed consent form to participate in the study. On the other hand, the exclusion criteria were symptoms of severe psychiatric disorders, taking the psychiatric drug, and missing more than two sessions in the educational classroom. Based on these criteria, 187 individuals were excluded and 3 individuals declined to participate, and finally 230 individuals ( 179 female and 51 male) enrolled in the study. They were randomly assigned to two experimental $(n=115)$ and control $(n=115)$ groups.

\section{Procedure}

Randomization was achieved using sealed numbered envelopes developed from a random number generator. A research assistant who was not involved in the recruitment of participants prepared the envelopes. Participants allocated to the control group $(\mathrm{n}=115)$ received standard care. Participants assigned to the intervention group $(\mathrm{n}=115)$ also received standard care plus the stress management intervention. Three months after the intervention, the posttest was conducted for both experimental and control groups to examine the effects of education on the primary and secondary outcomes. It is noteworthy that standard care in Iran includes weekly visits at a healthcare clinic from a doctor, a dietitian, and a nurse and lasts for less than $20 \mathrm{~min}$. These visits were held individually or in groups. Because of the nature of the intervention in the current study, the instructor was not blinded to group assignment, but participants and statistical investigator were blinded to group assignment.

\section{Research tools}

The primary outcomes of the current research include the Perceived Stress Scale, Endler and Parker's Coping Inventory for Stressful Situations, the Coping Self-Efficacy Scale, and the Multidimensional Scale of Perceived Social Support. The secondary outcome was HbA1c levels. HbA1c tests were conducted using a biosystem kit and chromatography method. Biosystem kits are standard kits approved by the Iranian Ministry of Health and Medical Education. The kit was used two times; before the beginning of the study and 3 months after the end of the intervention.

The following questionnaires were also used:

(1) The demographic questionnaire This questionnaire measures variables including age, gender, educational qualifications, duration of diabetes, body mass index (BMI), and marital status. BMI ranged 18.5-24.9 was considered as normal; under 18.5 as underweight, over 25 as overweight and over 30 as obese [6].

(2) The Perceived Stress Scale The Cohen's Perceived Stress Scale was used to measure perceived stress within the past month. It uses 14 items to measure thoughts and feelings about the events to control, overcome and to cope with the past mental stresses and distresses. It also examines the risk factors associated with behavioral disorders and reveals the process of stressful relationships. The scale uses a 5-point Likert scale and answers range from never (score 0 ), rarely (score 1 ), sometimes (score 2 ), often (score 3), and most times (score 4). The lowest possible score is 0 and the highest score is 56 [19]. Higher scores indicate higher levels of perceived stress. This questionnaire has been validated by Sigari et al. in Iran and its internal consistency has been confirmed (Cronbach's alpha coefficient $=0.90)$ [19]. In the present study, the internal consistency of the questionnaire was 0.88 .

(3) Endler and Parker's Coping Inventory for Stressful Situations (CISS): This scale contains 48 items and includes task-oriented coping strategies (16 items), emotion-oriented coping strategies (16 items), and avoidanceoriented coping strategies (16 items). The questionnaire uses a 5-point Likert scale and answers range from never (score 1) to always (score 5). The participants' scores determine which coping strategy better suits them. The lowest and the highest possible scores include 16 and 80 for each strategy [19]. The internal consistency of the Persian version of the questionnaire has been confirmed (Cronbach's alpha coefficient $=0.83$ ) [20]. In the present study, the Cronbach's alpha coefficients of $0.85,0.86,0.83$, and 0.82 were obtained for the whole scale, the problemfocused, the emotion-focused, and avoidance coping strategies, respectively.

(4) The Coping Self-Efficacy (CSE) Scale The CSE of Chesney et al. is a 26-item test, which is designed on an 11-point Likert scale ranged from (I can never cope with it (score 0) to I am sure that I can cope with it (score 10). This scale has three subscales; using problem-solving coping strategies (12 items), stopping negative thoughts and emotions (9 items), and gaining friends and family support (5 items). To calculate the total score of each sub-scale, the scores of all the items associated with the sub-scale must be added. Thus, the subscales 
of problem-solving coping strategies, stopping negative thoughts and emotions, and gaining friends and family support are ranged from 0 to 120,0 to 90 , and 0 to 50 , respectively [21]. Mahmoudi et al. measured the internal consistency of the above subscales for the Persian version of the questionnaire and obtained these coefficients: 0.84 , 0.83 , and 0.73 , respectively [21]. In the present study, the Cronbach's alpha coefficients of the subscales included $0.90,0.88$, and 0.85 , respectively.

The total score of each sub-scale is calculated by adding the scores of all the items associated with the sub-scale.

(5) The multidimensional scale of perceived social support (MSPSS) This scale contains 12 questions and measures three factors, including friends' support, family, and significant others. This scale uses a 7-point Likert scale and has an answer range from 0 to 6 (I strongly disagree to I strongly agree). The scores range from 0 to 72 . This scale has been validated by Bagherian-Sararoudi et al. [22] in Iran and its internal consistency has been confirmed (Cronbach's alpha coefficient $=0.84$ ). In the present study, the internal consistency of the questionnaire was 0.86 .

\section{Intervention}

The training sessions were performed in Zarandieh County Diabetes Clinic. The intervention program was developed based on the social cognitive theory and had an emphasis on improving self-efficacy and perceived social support. Participants in the experimental groups received eight sessions of one and a half hours educational sessions in groups of 6-10 persons. According to $\mathrm{SCT}$, the behavior is being learned within the context of social interactions, experiences, and media influence. Thus, people learn new behaviors by both trying them and subsequent outcome of the behaviors and also by observing the replication of the behavior by a third party or a role model. To increase relaxation self-efficacy, we focused on the antecedents (e.g., sources of information) that may be used to influence self-efficacy related to stress management and relaxation, performance accomplishment (e.g., past experience with relaxation and aggressiveness control), vicarious experience (e.g., observation of role models' relaxation technique practices), verbal persuasion (e.g., encouragement and support from others), and physiologic cues (e.g., anxiety and fatigue). Examples of the strategies used included providing information, discussion, and practice with a psychologist to enhance performance accomplishment in regard to relaxation; having a patient with diabetes attend the education session as a role model to demonstrate relaxation skills and answer questions (vicarious experience); giving positive verbal feedback (verbal persuasion); and providing anticipatory guidance to acknowledge and normalize relaxation challenges (decrease anxiety). To better influence supports from others, two educational sessions were held for participants spouses and significant others mentioned by them in the questionnaire to help patients with using relaxation techniques. Some training pamphlets and booklets were also provided for each patient. The information booklet, prepared by a health education specialist and validated by the expert panel, included written text (brief messages about diabetes self-care and relaxation) with illustrations to reinforce the information. The images of damaged human's body organs were accompanied by messages such as "by doing relaxation practices you reduce the risk of developing the end-stage disease and chronic conditions". A phone number had been written at the end of the booklet for participants who may seek more information.

The following eight group sessions were held with the help of a psychologist during a 1-month period (twice a week); session one: teaching muscle relaxation techniques as reported earlier [23], communication skills, and getting acquainted with external supportive agents; session two: social communication skills such as empathy; session three: examining the three factors effective in self-efficacy (thought, affection and action) and examining rational and irrational thinking; session four: providing strategies to cope with irrational thoughts and to replace them rational thoughts; session five: providing strategies to cope with irrational thoughts and to replace them rational thoughts; session six: teaching three coping strategies (aggressiveness, passiveness and assertiveness) and providing assertive strategies; session seven: introducing ineffective and effective strategies for coping with stressful situations (inefficient avoidance strategies, etc.) and finally session eight: providing strategies for coping with stress (problem-focused and emotion-focused coping strategies). The skills were then practiced using written scenarios.

\section{Data analysis}

The results were analyzed in SPSS 15 using paired and independent t-tests, Pearson correlation coefficient, and Chi square analysis. The significance level was considered at 0.05 . The Kolmogorov-Smirnov test was used to check the normality of data distribution.

\section{Ethical considerations}

This project is approved by the Ethics Committee of Saveh University of Medical Sciences (IR.SAVEHUMS. REC.1396.17). After granting the consent of the patients, the aim of the study, the methodology, and the advantages and disadvantages of the study were explained to them. The participants were assured that they are not obliged to participate in the research and that they can 
leave it whenever they wish. They were also assured of the confidentiality of their information.

\section{Results}

In total, 230 (179 female and 51 male) patients with type 2 diabetes were enrolled. Figure 1 shows a flow diagram of the participants during the study period.

The mean ages of patients in the experimental and control groups were $56.4 \pm 7.2$ and $57.1 \pm 6.5$ years, respectively. The demographic characteristics of the participants are presented in Table 1 . There was no statistically significant difference between the two groups in terms of age, gender, duration of diabetes, marital status, $\mathrm{BMI}$, and educational qualifications.

Based on the results, before the intervention, the mean perceived stress scores of the experimental and control groups were $33.9 \pm 4.6$ and $35 \pm 6.5$, respectively, with no statistically significant difference observed $(p=0.38)$. However, after the intervention, the mean perceived stress score of the experimental group $(26.7 \pm 4.7)$ was significantly less than that of the control group (34.5 \pm 7$)$ $(p=0.001)$. Before the intervention, the patients in the two groups were homogeneous in terms of various aspects of Coping Inventory for Stressful Situations (CISS) (task-oriented coping, emotion-oriented coping, and avoidance-oriented coping), various aspects of Coping Self-Efficacy (problem-solving coping strategies, stopping negative thoughts and emotions, and gaining friends and family support) and perceived social support. However, after the intervention, the independent $t$-test showed a significant difference between the mean scores of all aspects of Coping Inventory for Stressful Situations (CISS), coping self-efficacy, and perceived social support in the two groups $(\mathrm{p}<0.05)$ (Table 2$)$.

As shown in Table 3, before the intervention, the mean scores of HbA1c in the experimental and control groups were $8.52 \pm 1$ and $8.42 \pm 1.2$, respectively, and the independent $\mathrm{t}$-test showed no statistically significant difference between the two groups. However, after the intervention, the results showed a significant reduction in glycosylated hemoglobin levels in the experimental group ( $\mathrm{p} \leq 0.05)$. In addition, the paired $\mathrm{t}$-test showed a significant difference between the mean scores of HbA1c in the experimental group before and after the intervention while the difference was not statistically significant in the control group.

\section{Discussion}

In addition to the physical complications, diabetesinduced stress has some adverse psychiatric complications that make diabetes difficult to control in terms of identification and elimination processes [24]. In chronic diseases such as diabetes, psychotherapy can reduce the need for expensive medical services and increase the

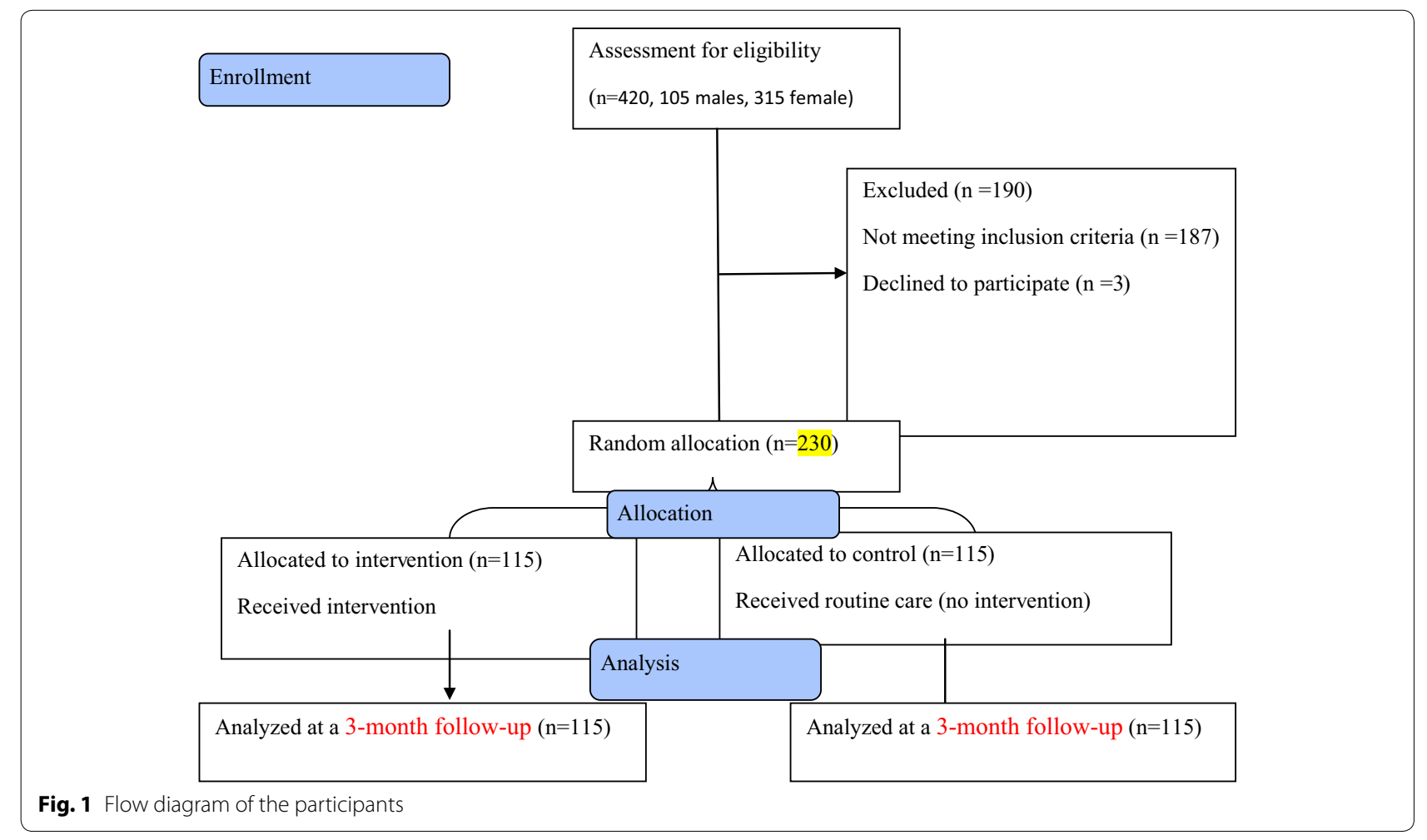


Table 1 The frequency distribution of the patients in the two groups based on the qualitative demographic variables

\begin{tabular}{|c|c|c|c|c|c|}
\hline \multirow[t]{2}{*}{ Group variable } & \multicolumn{2}{|c|}{$\begin{array}{l}\text { Experimental } \\
\text { group }\end{array}$} & \multicolumn{2}{|c|}{$\begin{array}{l}\text { Control } \\
\text { group }\end{array}$} & \multirow[t]{2}{*}{ P-value* } \\
\hline & No. & $\%$ & No. & $\%$ & \\
\hline \multicolumn{6}{|l|}{ Gender } \\
\hline Male & 23 & 20 & 28 & 24 & 0.526 \\
\hline Female & 92 & 80 & 87 & 76 & \\
\hline \multicolumn{6}{|l|}{ Marital status } \\
\hline Single & 18 & 15.6 & 14 & 12.2 & 0.568 \\
\hline Married & 97 & 84.4 & 101 & 87.8 & \\
\hline \multicolumn{6}{|l|}{ Educational qualifications } \\
\hline Illiterate & 6 & 5 & 5 & 4 & 0.849 \\
\hline $\begin{array}{l}\text { Elementary and middle } \\
\text { school }\end{array}$ & 62 & 54 & 59 & 51 & \\
\hline $\begin{array}{l}\text { Diploma and higher } \\
\text { degrees }\end{array}$ & 47 & 41 & 51 & 44 & \\
\hline \multicolumn{6}{|l|}{ Duration of diabetes (years) } \\
\hline$<2$ & 15 & 13 & 21 & 18 & 0.547 \\
\hline $2-4$ & 51 & 44 & 47 & 41 & \\
\hline$>4$ & 49 & 42 & 47 & 41 & \\
\hline \multicolumn{6}{|l|}{ Age (years) } \\
\hline$<30$ & 8 & 7 & 9 & 8 & 0.947 \\
\hline $31-49$ & 48 & 42 & 46 & 40 & \\
\hline$>50$ & 59 & 51 & 60 & 52 & \\
\hline \multicolumn{6}{|l|}{ BMI } \\
\hline Underweight & 5 & 4 & 6 & 5 & 0.956 \\
\hline Normal & 22 & 19 & 21 & 18 & \\
\hline Overweight & 52 & 45 & 49 & 43 & \\
\hline Obese & 36 & 32 & 39 & 34 & \\
\hline
\end{tabular}

Derived from Chi square

mental health of patients [25]; thus, this study focuses on Coping Inventory for Stressful Situations (CISS) and used self-efficacy and social support constructs to improve the condition of these patients.

The results showed that stress management techniques could help patients to control their blood glucose levels, which in turn can prevent long-term complications of diabetes, such as diabetic foot ulcer and blindness. Stratton believes that a $5 \%$ reduction in HbA1c levels is associated with a significant reduction in the risk of coronary artery disease. In line with the present study, Hamid's study in Iran showed that stress management training was effective in controlling blood glucose and decreasing depression, anxiety, stress, and HbA1c levels in diabetic women [26]. The study of Attari et al. also demonstrated the beneficial effects of stress management program in controlling blood glucose levels in diabetic patients [27]. In another study conducted by Surwit et al. at Duke
University Outpatient Clinics, the results showed that stress management training program is a useful and costeffective technique in reducing the HbA1c levels in diabetic patients [28]. The results of the present study, in line with the previous studies, highlight the importance of applying stress management techniques in controlling blood glucose levels in diabetic patients. Therefore, it seems that employing psychologists in diabetes clinics or holding retraining management courses for medical staff can improve the health of diabetic patients.

According to the cognitive theory, there is a strong negative correlation between self-efficacy and stress and the present research showed that people with higher levels of self-efficacy might better manage their stress. The present study also confirmed the negative correlation between self-efficacy and perceived stress [29]. After the intervention, the self-efficacy levels increased while the perceived stress and $\mathrm{HbA} 1 \mathrm{c}$ levels decreased significantly. Schwerdtfeger et al. found that high self-efficacy might act as a supportive factor for psychological wellbeing by strengthening the immune system, reducing the release of stress-related hormones, and improving the mental health of people [30]. In line with our results, Gao et al. found that higher levels of self-efficacy was associated with better self-care and decreased HbA1c levels in diabetic patients [18]. Similarly, Walker et al. in their study in the US found that higher levels of self-efficacy were associated with better self-care, better blood glucose control, and a higher quality of life of diabetic patients [31]. Al-Khawaldeh et al. in their study in Jordan found that higher levels of self-efficacy were associated with a daily walk, diet and drug control, and better control of the blood glucose levels in diabetic patients [32]. Schoenthaler et al. studied patients with chronic diseases and observed that patients with higher levels of self-efficacy better perform recommended health behaviors than those with lower levels [33].

Previous studies have shown that social support plays an important role in the self-care of patients with chronic diseases $[34,35]$. For example, a meta-analysis of 122 studies conducted by DiMatteo showed that adherence to medical regimens in patients with social support increases by $27 \%$ [36]. In line with previous studies, our results also showed that increasing perceived social support would decrease perceived stress levels in patients, which consequently results in a reduction in the HbA1c levels. Miller's study proved that social support can increase levels of self-esteem and self-efficacy as well as reducing levels of stress and depression among patients [37]. In the studies of Aikens et al. [38] and Pereira et al. [39], social support had the greatest correlation with blood glucose control. Glasgow and Toobert in their study showed that family support was the most 
Table 2 Comparison of constructs in two groups at baseline and 3-months follow-up

\begin{tabular}{|c|c|c|c|c|}
\hline Variable & Time group & Baseline mean $\pm S D$ & $\begin{array}{l}\text { 3-months follow-up } \\
\text { mean } \pm S D\end{array}$ & P-value* \\
\hline \multirow[t]{3}{*}{ Stress } & Experimental group & $4.6 \pm 33.9$ & $4.7 \pm 26.7$ & 0.001 \\
\hline & Control group & $6.5 \pm 35$ & $7 \pm 34.5$ & 0.14 \\
\hline & P-value** & 0.38 & 0.001 & - \\
\hline \multirow[t]{3}{*}{ Problem-Focused Coping Strategies } & Experimental group & $9 \pm 43.6$ & $3.9 \pm 51.4$ & 0.001 \\
\hline & Control group & $5.9 \pm 46.1$ & $8.1 \pm 45.7$ & 0.16 \\
\hline & P-value** & 0.13 & 0.001 & - \\
\hline \multirow[t]{3}{*}{ Emotion-Focused Coping Strategies } & Experimental group & $5.5 \pm 35.6$ & $4.9 \pm 42.9$ & 0.001 \\
\hline & Control group & $8.2 \pm 37.8$ & $8.1 \pm 38.8$ & 0.544 \\
\hline & P-value** & 0.17 & 0.009 & - \\
\hline \multirow[t]{3}{*}{ Avoidance-focused coping strategies } & Experimental group & $41.0 \pm 5.1$ & $2.7 \pm 45.3$ & 0.001 \\
\hline & Control group & $5.9 \pm 42.4$ & $4.9 \pm 41.6$ & 0.19 \\
\hline & P-value** & 0.29 & 0.001 & - \\
\hline \multirow[t]{3}{*}{ Self-efficacy use problem-focused coping } & Experimental group & $10.5 \pm 57.2$ & $11.4 \pm 67.3$ & 0.001 \\
\hline & Control group & $11.6 \pm 61.8$ & $11.2 \pm 60.7$ & 0.233 \\
\hline & P-value** & 0.07 & 0.02 & - \\
\hline \multirow[t]{3}{*}{ Self-efficacy stop unpleasant emotions and thoughts } & Experimental group & $9.2 \pm 51.3$ & $10.5 \pm 59.5$ & 0.001 \\
\hline & Control group & $11.2 \pm 52.1$ & $11.2 \pm 53.2$ & 0.234 \\
\hline & P-value** & 0.71 & 0.03 & \\
\hline \multirow{3}{*}{ Self-efficacy gaining friends and family support } & Experimental group & $8.1 \pm 28.5$ & $34.5 \pm 5.9$ & 0.001 \\
\hline & Control group & $9 \pm 31.9$ & $30.2 \pm 9.7$ & 0.08 \\
\hline & P-value** & 0.08 & 0.03 & \\
\hline \multirow[t]{3}{*}{ Social support } & Experimental group & $8.1 \pm 38.5$ & $6.3 \pm 46.7$ & 0.401 \\
\hline & Control group & $7.4 \pm 39.4$ & $8.4 \pm 40.3$ & 0.007 \\
\hline & P-value** & 0.63 & 0.004 & - \\
\hline
\end{tabular}

* Paired T-test; ** Independent T-test

Table 3 Comparison of glycosylated hemoglobin (HbA1c) levels in two groups at baseline and 3-months follow-up

\begin{tabular}{lllll}
\hline Variable & Time group & Baseline mean \pm SD & 3-months follow-up mean \pm SD & P-value* \\
\hline HbA1c & Experimental group & $8.52 \pm 1$ & $6.1 \pm 1$ & 0.001 \\
& Control group & $8.42 \pm 1.2$ & $8.21 \pm 1.31$ & 0.530 \\
& P-value** & 0.706 & 0.0001 & \\
\hline
\end{tabular}

important factor in adherence to strict diets as well as in blood glucose control [40]; however, the study of Chew et al. in Malaysia did not show any significant relationship between social support and blood glucose control. This contradictory conclusion may be due to the different tools used in Chew's study and because of discarding the variable of friends and family support [34]. A review study by Stopford et al. on 29 studies revealed that among the components of social support, family support is effective in reducing $\mathrm{HbA} 1 \mathrm{c}$ levels and in blood glucose control [35].

\section{Limitation}

Since the current research was performed in one geographical area in Iran, the generalizability of our results is decreased. Also, we followed up the patients for 3 months as the longer follow up may lead to more accurate outcomes. In addition, other factors that can affect the results such as diet and physical activity were not measured in this study, and thus could be addressed in future studies. 


\section{Conclusion}

Our results suggested that the theory-based stress management intervention based on social cognitive theory may help to decrease stress and coping self-efficacy, stress management, and perceived social support and lead to a reduction of the glycosylated hemoglobin levels among patients with diabetes in Zarandieh, Iran.

\section{Abbreviations}

CISS: Coping Inventory For Stressful Situations; CSE: Coping Self-Efficacy; BMI: body mass index; CVR: content validity ratio; CVI: content validity index.

\section{Authors' contributions}

The authors' responsibilities were as follows: MA was supervisors of the study. MK, FZ-A and HK designed and conducted the study. All authors contributed the data analysis and assisted in the preparation of the final version of the manuscript. MA provided the final version of the manuscript. All authors read and approved the final manuscript.

\section{Authors' information}

FZ-A is a Health Education and Promotion Specialist at Public Health School, Isfahan University of Medical Sciences, MA is a Health Education and Promotion Specialist at Public Health School, Ahvaz Jundishapur University of Medical Sciences, Ahvaz, Iran.MK and HK are assistant professors at Saveh University of Medical Sciences, Saveh, Iran.

\section{Author details}

${ }^{1}$ Department of Health Education and Promotion, School of Health, Isfahan University of Medical Sciences, Isfahan, Iran. ${ }^{2}$ Social Determinants of Health Research Center, Ahvaz Jundishapur University of Medical Sciences, Ahvaz, Iran. ${ }^{3}$ Department of Health Education and Promotion, Public Health School, Ahvaz Jundishapur University of Medical Sciences, Ahvaz, Iran. ${ }^{4}$ Social Determinants of Health Research Center, Saveh University of Medical Sciences, Saveh, Iran.

\section{Acknowledgements}

We would like to thank all patients who participated in this study. We also express our gratitude to Professor Ali Montazeri for his valuable comments on the earlier version of the manuscript.

\section{Competing interests}

The authors declare that they have no competing interests.

\section{Availability of data and materials}

Upon request, we can offer onsite access to external researchers to the data analyzed at Ahvaz Jundishapur University of Medical Sciences, Ahvaz, Iran.

\section{Consent for publication}

Not applicable.

\section{Ethics approval and consent to participate}

All participants were informed about the study and confidentiality protocols. Informed consent was obtained from all the participants. The Ethics Committee of Saveh Jundishapur University of Medical Sciences confirmed the morality and ethics of that study; IR.SAVEHUMS.REC.1396.17.

\section{Funding}

No financial support was received for this research.

\section{Publisher's Note}

Springer Nature remains neutral with regard to jurisdictional claims in published maps and institutional affiliations.

Received: 10 January 2018 Accepted: 30 April 2018

Published online: 08 May 2018

\section{References}

1. Zareban I, Karimy M, Niknami S, Haidarnia A, Rakhshani F. The effect of self-care education program on reducing $\mathrm{HbA} 1 \mathrm{c}$ levels in patients with type 2 diabetes. J Educ Health Promot. 2014;3:123.

2. Nasli-Esfahani E, Farzadfar F, Kouhnavard M, Ghodssi-Ghassemabadi R, Khajavi A, Peimani M, Razmandeh R, Vala M, Shafiee G, Rambod C. Iran diabetes research roadmap (IDRR) study: a preliminary study on diabetes research in the world and Iran. J Diabetes Metab Disord. 2017;16(1):9.

3. Bianco A, Pomara F, Thomas E, Paoli A, Battaglia G, Petrucci M, Proia P, Bellafiore M, Palma A. Type 2 diabetes family histories, body composition and fasting glucose levels: a cross-section analysis in healthy sedentary male and female. Iran J Public Health. 2013;42(7):681.

4. Zareban I, Niknami S, Hidarnia A, Rakhshani F, Shamsi M, Karimy M. Effective intervention of self-care on glycaemia control in patients with type 2 diabetes. Iran Red Crescent Med J. 2014;16(12):8311.

5. Shaw JE, Sicree RA, Zimmet PZ. Global estimates of the prevalence of diabetes for 2010 and 2030. Diabetes Res Clin Pract. 2010;87(1):4-14.

6. Karimy M, Araban M, Zareban I, Taher M, Abedi A. Determinants of adherence to self-care behavior among women with type 2 diabetes: an explanation based on health belief model. Med J Islam Repub Iran. 2016;30:368.

7. Zareban I, Niknami S, Hidarnia A, Rakhshani F, Karimy M, Shamsi M. The effect of education program based on health belief model on decreasing blood sugar levels in diabetic type 2 patients in Zahedan. Health Scope. 2013;2(2):73-8

8. Alonso-Morán E, Satylganova A, Orueta JF, Nuño-Solinis R. Prevalence of depression in adults with type 2 diabetes in the Basque Country: relationship with glycaemic control and health care costs. BMC Public Health. 2014;14(1):769.

9. Brannon L, Feist J, Updegraff JA. Health psychology: an introduction to behavior and health. Boston: Cengage Learning; 2013.

10. Eren I, Erdi O, Ozcankaya R. Relationship between blood glucose control and psychiatric disorders in type II diabetic patients. Turk psikiyatri dergisi [Turkish journal of psychiatry]. 2003;14(3):184-91.

11. Pitts M, Phillips K. The psychology of health: an introduction. Abingdon: Psychology Press; 1998.

12. Chrousos $\mathrm{G}$. The role of stress and the hypothalamic-pituitary-adrenal axis in the pathogenesis of the metabolic syndrome: neuro-endocrine and target tissue-related causes. Int J Obes. 2000;24(S2):S50.

13. Emelyanova L, Petrovic M, Holmuhamedov E, Rizvi F, Ross G, Kress DC, Tajik AJ, Jahangir A. Diabetes mellitus is associated with impaired mitochondrial oxidative phosphorylation system and increased oxidative stress in human atria. J Am Coll Cardiol. 2016;67(13 Supplement):1394.

14. van Son J, Nyklíček I, Pop VJ, Pouwer F. Testing the effectiveness of a mindfulness-based intervention to reduce emotional distress in outpatients with diabetes (DiaMind): design of a randomized controlled trial. BMC Public Health. 2011;11(1):131.

15. Braun A, Sämann A, Kubiak T, Zieschang T, Kloos C, Müller UA, Oster P, Wolf G, Schiel R. Effects of metabolic control, patient education and initiation of insulin therapy on the quality of life of patients with type 2 diabetes mellitus. Patient Educ Couns. 2008;73(1):50-9.

16. Araban M, Baharzadeh K, Karimy M. Nutrition modification aimed at enhancing dietary iron and folic acid intake: an application of health belief model in practice. Eur J Pub Health. 2017;27(2):287-92.

17. Park K, Seo K, Kim B, Lee Y, Lim A, Song Y. The associations among diabetes exercise self-efficacy, the needs for exercise and perceived health status in patients with diabetes. J Adv Res Dyn Control Syst. 2017;10(Special Issue).

18. Gao J, Wang J, Zheng P, Haardörfer R, Kegler MC, Zhu Y, Fu H. Effects of self-care, self-efficacy, social support on glycemic control in adults with type 2 diabetes. BMC Fam Pract. 2013;14(1):66.

19. Sigari N. Reliability and validity of Persian version of perceived stress scale (PSS-10) in adults with asthma. Arch Iran Med. 2014;17(5):361.

20. Ghoreyshi Rad F. Validation of endler and parker coping scale of stressful situations. Olome Tarbiyati. 2010;1:1-7.

21. Mahmoudi M, Shojaezadeh D, Dehdari T, Hajizadeh E, Taghdisi MH, Abbasian L, Roohi M. psychometric properties of the Coping Self-Efficacy scale among HIV-infected Iranian patients. Iran Red Crescent Med J. 2015;17(2):e25074. 
22. Bagherian-Sararoudi R, Hajian A, Ehsan HB, Sarafraz MR, Zimet GD. Psychometric properties of the Persian version of the multidimensional scale of perceived social support in Iran. Int J Prev Med. 2013;4(11):1277.

23. Koloverou E, Tentolouris N, Bakoula C, Darviri C, Chrousos G. Implementation of a stress management program in outpatients with type 2 diabetes mellitus: a randomized controlled trial. Hormones. 2014;13(4):509-18.

24. Stratton IM, Adler Al, Neil HAW, Matthews DR, Manley SE, Cull CA, Hadden D, Turner RC, Holman RR. Association of glycaemia with macrovascular and microvascular complications of type 2 diabetes (UKPDS 35): prospective observational study. BMJ. 2000;321(7258):405-12.

25. Shapiro SL, Astin JA, Bishop SR, Cordova M. Mindfulness-based stress reduction for health care professionals: results from a randomized trial. Int J Stress Manage. 2005;12(2):164.

26. Hamid N. Effects of stress management training on glycemic control in women with type 2 diabetes. Iran J Endocrinol Metab. 2011;13(4):346-53.

27. Attari A, Sartippour M, Amini M, Haghighi S. Effect of stress management training on glycemic control in patients with type 1 diabetes. Diabetes Res Clin Pract. 2006;73(1):23-8

28. Surwit RS, Van Tilburg MA, Zucker N, McCaskill CC, Parekh P, Feinglos MN, Edwards CL, Williams P, Lane JD. Stress management improves long-term glycemic control in type 2 diabetes. Diabetes Care. 2002;25(1):30-4.

29. Torres JB, Solberg VS. Role of self-efficacy, stress, social integration, and family support in Latino college student persistence and health. J Vocat Behav. 2001;59(1):53-63.

30. Schwerdtfeger A, Konermann L, Schönhofen K. Self-efficacy as a healthprotective resource in teachers? A biopsychological approach. Health Psychol. 2008;27(3):358.

31. Walker RJ, Smalls BL, Hernandez-Tejada MA, Campbell JA, Egede LE. Effect of diabetes self-efficacy on glycemic control, medication adherence, self-care behaviors, and quality of life in a predominantly low-income, minority population. Ethn Dis. 2014;24(3):349-55.

32. Al-Khawaldeh OA, Al-Hassan MA, Froelicher ES. Self-efficacy, self-management, and glycemic control in adults with type 2 diabetes mellitus. J Diabetes Complications. 2012;26(1):10-6.

33. Schoenthaler A, Ogedegbe G, Allegrante JP. Self-efficacy mediates the relationship between depressive symptoms and medication adherence among hypertensive African Americans. Health Educ Behav. 2009;36(1):127-37.

34. Chew B, Khoo E, Chia Y. Social support and glycemic control in adult patients with type 2 diabetes mellitus. Asia Pac J Public Health. 2015;27(2):NP166-73.

35. Stopford R, Winkley K, Ismail K. Social support and glycemic control in type 2 diabetes: a systematic review of observational studies. Patient Educ Couns. 2013;93(3):549-58.

36. DiMatteo MR. Social support and patient adherence to medical treatment: a meta-analysis. In.: Am Psychol Assoc; 2004.

37. Miller TA, DiMatteo MR. Importance of family/social support and impact on adherence to diabetic therapy. Diabetes Metab Syndr Obes. 2013:6:421.

38. Aikens JE, Bingham R, Piette JD. Patient-provider communication and self-care behavior among type 2 diabetes patients. Diabetes Educ. 2005;31(5):681-90

39. Pereira MG, Berg-Cross L, Almeida P, Machado JC. Impact of family environment and support on adherence, metabolic control, and quality of life in adolescents with diabetes. Int J Behav Med. 2008;15(3):187-93.

40. Glasgow RE, Toobert DJ. Social environment and regimen adherence among type II diabetic patients. Diabetes Care. 1988;11(5):377-86.
Ready to submit your research? Choose BMC and benefit from:

- fast, convenient online submission

- thorough peer review by experienced researchers in your field

- rapid publication on acceptance

- support for research data, including large and complex data types

- gold Open Access which fosters wider collaboration and increased citations

- maximum visibility for your research: over $100 \mathrm{M}$ website views per year

At $\mathrm{BMC}$, research is always in progress.

Learn more biomedcentral.com/submissions 